endodontology's most important disease in order to promote ever better approaches to its diagnosis, prevention, and therapy'

The update of this textbook comes 12 years after the second edition. Previously co-edited by the late Thomas R. Pitt Ford, the new edition builds on his legacy. The chapters have been rearranged and rewritten by, in the main, different authors with a completely new chapter on the 'Biological basis for endodontic repair and regeneration'. The Foreword highlights the growth in the output of publications on endodontics with a staggering 14,685 being counted between 2008 and 2017 compared to a mere 6,525 between 1998 and 2007. Dag Ørstavik argues from this the necessity of a textbook to compress this knowledge for the novice and provide a 'backbone of knowledge and insights. The publication is accompanied on its companion website by a number of downloadable figures. This book can also be read as part of the library's ebook collection - www.bda.org/ebooks.

\section{Conservative Dentists group launched}

Conservative Dentists (CD) was recently launched at a sold-out event entitled 'Prevention is better than Cure', at the Palace of Westminster. There will be little disagreement that there is a lack of representation for dentists within all the political parties and Conservative Dentists was set up to combat this. The aims of the organisation are to form a bridge between the dental and political worlds thereby improving dialogue between the two and helping to influence policy.

The audience was diverse and varied, with representation from the British Dental Association (BDA), British Society of Paediatric Dentistry (BSPD), Public Health England and others and members were given the opportunity to question a panel which included the Minister for Dentistry Jo Churchill, the Chief Dental Officer (CDO) Sara Hurley, and MPs in the room, and raise the issues they were concerned about within dentistry. The discussion quickly jumped to water fluoridation and Jo Churchill, Sara Hurley and Sir Paul Beresford MP (the only practising dentist who is also an MP) made a plea for dentists to back fluoridation with the room being in consensus. Sir Paul recently made a parliamentary intervention stating that community water fluoridation is a well discussed public health tool and that 'at the moment there's an atmosphere that we can push through water fluoridation in this government. We have a unique opportunity, let's grab it'.

Jo Churchill said: 'Water fluoridation is the quickest and easiest way to improve our oral health, but we would really like [the dental profession's] help; we need dentists to talk to their patients about the benefits of water fluoridation. We need to move the dial, so the next generation can benefit from great oral health.'

To take the momentum within the room forward attendees were asked to give feedback on the state of dentistry in the UK and what policy ideas should be implemented to improve the provision of dental care. This will be collated and a report presented to the $\mathrm{CDO}$ and the Minister for Dentistry with future events planned accordingly. If you would like to get involved or join Conservative Dentists please contact: sejalbhansali@ymail.com.

This report was written by Sejal Bhansali, Chair and Founder of CD.

\section{New Masters of Surgery in Aesthetics launched}

University College London (UCL) will be the first ever global academic institution to offer a comprehensive Masters of Surgery (MS) in Aesthetics.

September 2021 will see the introduction of the programme at UCL's Division of Surgery \& Interventional Science. The new programme will include two courses: Master of MS in 1) Aesthetic Surgery and 2) Minimally-Invasive Aesthetics.

The programme will be led by Professor Afshin Mosahebi and include blended learning with 12 days of face to face teaching at UCL's world-leading faculty in aesthetic surgery and non-surgical aesthetics at the Royal Free Hospital - for practical skills-based sessions as well as remote on-line learning

Currently there is an absence of any standards or accredited training for non-surgical cosmetic procedures. The current regulatory framework places no restrictions on who may perform non-surgical cosmetic procedures. No qualifications are required to carry out these procedures and, in the absence of accredited training courses, anyone can set up a training course purporting to offer a qualification. As a result, a number of self-accredited training organisations have sprung up.

Aesthetic surgery and regenerative medicine have emerged as key growth areas within healthcare delivery across the world. An increasing number of healthcare professionals now offer treatments designed to refresh facial and overall appearance by surgery or minimally invasive procedures (immobilising facial muscles or providing dermal fillers).

As this sector of medicine is outside of the NHS in the UK, its governance and standards of care have been the focus of much debate over recent years. In an attempt to combat this, there is a growing push to fully legitimise this sector of medicine with the British Association of Aesthetic Surgeons (BAAPS) advising patients to ensure that their surgeon or practitioner is fully licensed and accredited and they are in full support of the programme.

BAAPS is supportive of the UCL Masters endeavour which helps to improve the standards of training in the aesthetic field. BAAPS research strategy will help to form the research element of the Masters and direct the future improvement and safety of aesthetic practice. 